\title{
Rumah Bugis sebagai Bentuk Pemertahanan Budaya Masyarakat Bugis di Desa Kemojan Karimunjawa
}

\author{
Titiek Suliyati \\ Program Studi Sejarah Fakultas Ilmu Budaya Universitas Diponegoro Semarang, \\ Jl. Prof. Soedarto, SH, Kampus Undip Tembalang, Semarang 50275 \\ Email: suliyati.titiek@gmail.com
}

\begin{abstract}
This paper examines the Bugis house in the Kemojan Village of Karimunjawa as a form of cultural retention of the Bugis people. The efforts of the Bugis community of Kemojan Karimunjawa Village maintain the preservation of the Bugis house as their residence because they try to maintain their culture. Besides that they want to introduce to the people around them their identity through the philosophy contained in the construction of Bugis houses. Although the Bugis house in Kemojan Village is different from the Bugis house in South Sulawesi, but in principle the philosophy and concept of development are the same. The development of tourism which is rampant in Karimunjawa has caused Bugis people in Kemojan Village to take the initiative to build several Bugis houses on the beach for Home Stay. Home Stay was built in accordance with the rules and forms of Bugis houses in Sulawesi. With the existence of Bugis houses for the sake of this tourism, it is hoped that the public will get to know the Bugis culture overseas
\end{abstract}

Keywords: House Bugis, Cultural Retention, Bugis Community

\section{Pendahuluan}

Sejak awal kehidupan manusia memerlukan tempat bernaung, berteduh dan berkumpul bersama keluarga. Rumah merupakan bentuk eksistensi keberadaan keluarga dan dapat memenuhi semua kebutuhan manusia terhadap kenyamanan dan keamanan. Rumah dapat berfungsi sebagai tempat untuk menikmati kehidupan yang nyaman, tempat untuk beristirahat, tempat berkumpulnya keluarga dan tempat untuk menunjukkan tingkat sosial dalam masyarakat. Perkembangan bentuk rumah mengikuti budaya dan tradisi yang dianut.

Suku-suku Indonesia memiliki rumah-rumah yang khas yang menjadi ciri kesukuannya, salah satu suku yang memiliki rumah khas adalah suku Bugis. Suku Bugis yang dikenal sebagai perantau, di tanah perantauan membangun rumah dengan tetap mempertahankan ciri rumah asli dari tanah asalnya. Di beberapa wilayah di Indonesia yang menjadi tempat perantauan suku Bugis, masih kita dapati rumah-rumah tradisional Bugis yang berbentuk rumah panggung. Salah satu daerah yang menjadi tempat perantauan suku Bugis adalah Dusun Batu Lawang Desa Kemojan di Karimunjawa.

Adat istiadat dan kepercayaan adalah warisan nenek moyang yang menjadi inti kebudayaan. Adat istiadat menjadi pedoman yang penting dalam berpikir dan bertindak di lingkungan masyarakat Bugis. Adat istiadat berfungsi untuk mengatur dan mengarahkan perilaku, cara berinteraksi dan cara membangun rumah dan membagi ruang sesuai dengan kebutuhan penghuninya. Bentuk fisik rumah tradisional merupakan ekspresi adat istiadat dan kepercayaan (Wasilah \& Hildayanti, $2016: 71$ ).

Setiap rumah tradisional memiliki bentuk, tata ruang spasial, ornamen, dan sebagainya yang berbeda. Hal ini disebabkan adat istiadat dan kepercayaan nenek moyang masyarakat 


\section{E-ISSN : 2599-1078}

berbeda pula. Hal ini tampak pada rumah tradisional. Bugis yang berbeda bentuknya dari rumah-rumah tradisional sukuk-suku lain.

Rapoport (1969) menyebutkan, bahwa rumah dan lingkungan mengekspresikan budaya masyarakat. Budaya merupakan cara hidup yang khas, yang berkaitan dengan simbol dan kerangka pikir, dan cara beradaptasi dengan lingkungan. Budaya menjadi faktor yang paling penting dalam membentuk sebuah rumah. Hal ini terjadi pada suku Bugis yang melakukan adaptasi dengan lingkungan sekitar ketika akan membangun rumah Bugis sebagai tempat tinggalnya di Dusun Batulawang Desa Kemojan Karimunjawa. Suku Bugis membangun rumah Bugis sebagai identitas budayanya menyesuaikan dengan kondisi alam Desa Kamojan yang bukan sebagai daerah penghasil kayu. Kondisi alam Desa Kemojan yang demikian ini menyebabkan orang-orang Bugis membangun rumah panggung tidak setinggi rumah panggung yang ada di Sulawesi Selatan. Dengan bentuk rumah panggung yang tidak setinggi rumah panggung Bugis di Sulawesi Selatan, rumah Bugis di Desa Kemojan memiliki aturan dan pembagian ruang yang berbeda dengan bentuk rumah Bugis yang ada di Sulawesi Selatan.

Di Desa Kemojan saat ini masih tersisa tidak kurang dari 100 rumah Bugis yang dibangun sejak awal kedatangan mereka di Kemojan. Rumah-rumah Bugis di Kemojan memiliki bentuk yang agak berbeda dengan rumah Bugis di tempat asalnya.

Suku Bugis pada awal kedatangannya ke Desa Kemojan Karimunjawa membangun rumah dengan model rumah panggung karena beberapa alasan, yaitu mereka hanya memiliki ketrampilam membangun rumah sepertri model rumah Bugis.Selain itu dengan membangun rumah tinggal model rumah panggung menjadikan mereka merasa seperti di tanah asalnya, dan yang tak kalah penting adalah bahwa mereka ingin menunjukkan rumah Bugis yang unik kepada suku-suku lain yang tinggal di Kemojan.

Beberapa kajian tentang masyarakat Bugis di Desa Kemojan telah dilakukan yaitu antara lain kajian yang dilakukan oleh Puguh, Amaruli dan Utama (2016), tentang strategi adaptasi ekonomi nelayan Bugis Batulawang dan Latief (2016) melakukan kajian komunikasi beda gender dalam masyarakat bugis di Desa Kemujan Kepulauan Karimunjawa. Demikian juga Suliyati (2016) melakukan kajian tentang etnis Bugis di kepulauan Karimunjawa, terkait dengan harmoni dalam pelestarian budaya dan tradisi. Berbeda dengan tiga kajian tersebut di atas, artikel ini menyoroti tentang upaya masyarakat Bugis mempertahankan salah satu budayanya yaitu rumah Bugis.

Permasalahan yang dikaji dalam artikel ini adalah bagaimana masyarakat suku Bugis di Desa Kemojan mempertahankan keaslian bentuk rumah Bugis di tengah arus komunikasi, informasi yang intensif serta interaksi sosial dengan anggota masyarakat lain.

Untuk menjawab permasalahan tersebut, kajian ini dilakukan dengan tujuan mengetahui latar belakang dan upaya dan yang dilakukan masyarakat suku Bugis dalam mempertahankan rumah Bugis di Desa Kemojan.

\section{Metode}

Sejalan dengan permasalahan dan tujuan yang hendak dicapai dari penelitian ini, maka metode penelitian yang digunakan adalah metode kualitatif deskriptif dengan pendekatan sejarah dan sosiologi (Marvati,2004). Metode kualitatif digunakan karena penelitian ini berusaha mengungkap permasalahan sosial yang ditulis secara rinci (Creswell, 2008). Penelitian ini bersifat deskriptif untuk membantu penulis menggambarkan secara faktual hubungan antar instrument yang diteliti.

Metode kualitatif deskriptif ini dimaksudkan agar dapat memberikan pemahaman yang lebih baik tentang proses pembentukan dan perkembangan rumah Bugis di Desa Kemojan Karimunjawa. Pendekatan historis digunakan untuk mengumpulkan, menyeleksi, 
dan menguji secara kritis sumber-sumber sejarah, sehingga menghasilkan fakta sejarah. Fakta-fakta sejarah kemudian dianalisis dalam suatu uraian sistematis melalui pendekatan budaya.

Analisis dilakukan melalui metode analisis kualitatif yang mencakup tiga kegiatan yaitu reduksi data, penyajian data, dan penarikan simpulan (Miles dan Huberman, 1992: 1619). Reduksi data dilakukan dengan menyeleksi data yang sesuai dengan materi kajian dan kesesuainya dengan kerangka konseptual dalam kajian ini. Data yang telah tersusun secara krononogis dalam hubungan sebab-akibat didiskripsikan dan disajikan dalam bentuk narasi (Louis Gottschalk, 2008). Penarikan simpulan dan verifikasi dilakukan dengan mengoreksi dan memeriksa kembali kesesuaian data yang diperoleh melalui wawancara dan studi pustaka dengan sumber-sumber data lainnya. Verifikasi dilakukan dengan melakukan perbandingan antara kajian ini dengan dengan kajian-kajian lain yang sejenis

Sumber data dalam penelitian ini diperoleh dari buku, artikel dan hasil-hasil penelitian yang pernah dilakukan dengan menggunakan analisis deskriptif historis, yaitu suatu upaya menggambarkan proses pembentukan dan perkembangan rumah Bugis Kemojan karimunjawa. Selain itu data diperoleh melalui interview (wawancara), data lapangan berupa catatan-catatan, foto, dokumen pribadi (Danim, 2002:51).

\section{Hasil dan Pembahasan}

\subsection{Gambaran Umum Dusun Batulawang, Desa Kemujan Karimunjawa}

Desa Kemojan merupakan salah satu desa di Kepulauan Karimunjawa, Kabupaten Jepara. Luas wilayah Desa Kemojan adalah 1626 ha. Dari luas wilayah tersebut, 135 ha digunakan untuk pemukiman penduduk, 254 ha untuk ladang atau tegalan sebesar, dan 1066 ha untuk perkebunan.

Desa Kemojan dulu berpisah dengan Pulau Karimunjawa, namun karena terjadi sedimentasi Desa Kemojan dan Pulau Karimunjawa menyatu. Jumlah penduduk Desa Kemojan 3.118 jiwa terdiri dari 1.587 laki - laki serta 1.531 perempuan. Penduduk Desa Kemujan terdiri dari beberapa suku antara lain Jawa, Madura, dan Bugis serta sedikit suku Mandar. Mayoritas penduduk beragama Islam, hal ini tampak dari jumlah masjid 6 buah dan mushola 12 buah. Selain Islam agama yang dianut oleh penduduk Kemojan adalah agama Kristen (Data Kantor Petinggi Kemojan 2015)

Desa Kemojan terdiri dari empat dusun yaitu Dusun Kemojan, Dusun Telaga, Dusun Mrican dan Dusun Batulawang. Di Desa Kemujan terdapat 1072 kepala keluarga. Letak Desa Kemojan di utara kepulauan Karimunjawa menyebabkan masyarakat Bugis masih mempertahankan kebudayaan Bugis. Pemukiman yang terdapat di desa Kemojan mengikuti alur jalan. Jarak dari satu rumah dengan rumah lain agak berjauhan karena jumlah penduduk tidak terlalu banyak

\subsection{Suku Bugis di Kemojan Karimunjawa}

Sumber-sumber sejarah dan bukti-bukti tertulis tentang awal kedatangan suku Bugis ke Karimunjawa dan kemudian menetap di beberapa wilayah di sana, tidak diperoleh. Informasi tentang keberadaan suku Bugis di Karimunjawa, khususnya Desa Kemojan, diperoleh melalui wawancara sejarah lisan dengan beberapa tokoh masyarakat dan keturunan beberapa pendahulu yang mengetahui informasi tentang sejarah leluhur mereka di Desa kemojan.

Dari beberapa literatur diketahui, bahwa pada abad XV telah terjadi migrasi orang orang Bugis dari tempat asalnya menuju ke berbagai tempat di Nusantara. Migrasi ini 


\section{E-ISSN : 2599-1078}

dilakukan karena di Sulawesi Selatan saat itu terjadi konflik antarkerajaan yang menyebabkan situasi tidak aman bagi masyarakat Bugis. Selain kondisi tersebut, dorongan untuk mencari kehidupan yang lebih nyaman, juga mendorong masyarakat Bugis merantau (Kesuma, 2004 : 136-137). Sebuah sumber menginformasikan bahwa orang Bugis diperkirakan telah melakukan pelayaran ke kepulauan Karimunjawa pada abad ke-17 dan 18 (Suliyati, 2014). Informasi ini belum dapat sepenuhnya dipercayai karena belum ada data pendukung yang dapat memberi gambaran memadai mengenai masalah itu.

Pada awal perantauannya suku Bugis belum mengetahui tentang Karimunjawa, sehingga Karimunjawa tidak menjadi tujuan utama perantauannya. Perjalanan perantauan suku Bugis pada awalnya menuju pulau Masalembo, yang masuk wilayah Jawa Timur. Ternyata pulau tersebut sudah padat dan tidak ada lahan kosong bagi mereka. Dari beberapa perantau mereka mendengar bahwa ada tempat cukup luas untuk pemukiman yaitu Kepulauan Karimunjawa, sehingga kemudian para perantau Bugis banyak yang berlayar ke Karimunjawa. Karimunjawa dianggap sebagai tempat yang cocok untuk bermukim dan mencari penghidupan, karena selain belum banyak penghuninya, alamnya tenang dan memberi harapan untuk mencari penghidupan yang layak.

Di Karimunjawa suku Bugis tersebar di beberapa pulau seperti pulau Parang, Pulau Genting, pulau Nyamuk dan Desa Kemojan. Jumlah terbesar masyarakat Bugis berdiam di Desa kemojan.

Dari beberapa wawancara yang dilakukan dengan tokoh masyarakat Bugis di Desa Kemojan diperoleh informasi, bahwa orang Bugis yang pertama sampai di Karimunjawa dan berdiam di Desa Kemojan adalah Leindra. Diperkirakan awal kedatangan Suku Bugis di Desa Kemojan pada 1930 yaitu yang ditandai peristiwa "Babat Alas" yang dilakukan pertama kali oleh Leindra. Pada tahun-tahun berikutnya berdatangan suku Bugis yang di pimpin Garusang, disusul oleh Ali Caco. Suku Bugis yang ada di Kemojan saat ini adalah generasi keempat keturunan dari para tokoh Bugis tersebut di atas. Setelah kedatangan suku Bugis di Desa Kemojan, hutan dan semak-semak dibuka menjadi lahan pemukiman, pertanian dan perkebunan (Wawancara dengan Abdullah, tanggal 12 Maret 2019).

Secara umum masyarakat Bugis di Karimunjawa dapat hidup rukun dan harmonis dengan suku-suku lain seperti Jawa, Mandar dan Madura. Masyarakat Bugis masih memegang teguh falsafah kehidupan yang diajarkan oleh leluhur mereka, yaitu "dimana bumi dipijak, di situ langit dijunjung". Makna dari falsafah tersebut adalah, bahwa orang Bugis harus bisa menyesuaikan diri dengan lingkungan dan masyarakat setempat. Oleh karena falsafah ini diterapkan oleh mayoritas masyarakat Bugis, maka adaptasi lingkungan sangat mudah mereka lakukan .

Penyesuaian diri masyarakat Bugis dengan lingkungan yang baru secara harmonis juga didasari oleh sifat-sifat lain yang diajarkan oleh para orang tua, yaitu: (1) Sipakatau, yaitu penghargaan kepada orang lain dengan segala kelebihan dan kekurangannya. Ajaran ini menekankan pada perilaku yang baik terhadap sesama manusia. (2) Sipakalebi, yaitu sifat yang senang memberikan penghargaan atas kelebihan orang lain, misalnya dengan memberikan pujian dan menyenangkan orang lain. (3) Sipakainge, yaitu sifat terbuka untuk memberikan masukan atau kritik yang membangun terhadap orang lain maupun terdadap dirinya (http://ace-informasibudaya.blogspot.com, diunduh 1 Mei 2019)

Walaupun masyarakat Bugis di Desa Kemojan selalu menjaga harmoni dengan lingkungan masyarakat di tempat yang baru, tetapi mereka tidak tinggal diam bila masyarakat di lingkungannya yang baru merendahkan martabat mereka. Masalah yang dapat memicu ketidakharmonisan antarmasyarakat biasanya karena masalah yang terkait dengan siri. Bagi masyarakat Bugis siri adalah jiwa, harga diri mereka dan martabat yang harus ditegakkan. Bila harga diri dan martabat mereka direndahkan, maka mereka akan membela dan mau mengorbankan jiwanya demi menegakkan siri (Abdullah, 1985 : 37). 


\subsection{Rumah Bugis Sebagai Salah Satu Identitas Suku Bugis di Desa Kemojan Karimunjawa}

Dalam kehidupan sosial masyarakat Bugis, status pemilik rumah menentukan jenis rumah yang ditempati. Bila seseorang memiliki status yang tinggi seperti raja dan keturunannya serta bangsawan, maka rumah yang ditempati disebut sao raja. Rumah yang ditempati masyarakat awam disebut bola (Anwar, 2007). Tidak ada perbedaan yang besar antara sao raja dan bola bila dilihat dari bentuk bangunan rumah. Perbedaannya hanya pada ukuran rumah, yaitu sao raja ukurannya lebih besar daripada bola. Perbedaan bangunan rumah yang penting adalah pada ukuran luas dan jumlah tiang penyangga yang disebut timba sila/sambulayang. Semakin banyak jumlah timba sila menunjukkan status sosial pemilik rumah juga semakin tinggi (Jumran, 2010).

Di Desa Kemojan tidak kita temui rumah jenis sao raja, karena memang para perantau Bugis sejak awal tidak ada yang berasal dari ketutunan raja atau bangsawan. Rumah Bugis di Desa Kemojan adalah bola.

Pelras (2006: 265) mengatakan, bahwa rumah tradisional Bugis merupakan rumah panggung yang terbuat dari kayu. Atapnya terbuat dari sirap, rumbia atau seng. Bentuk atapnya berlereng dua yang dihubungkan dengan bubungan yang memanjang ke belakang. Kerangkanya berbentuk huruf " $\mathrm{H}$ ", berupa tiang dan balok yang disambung tanpa menggunakan pasak atau paku. Tiang-tiang inilah yang menopang dan menyangga lantai dan atap. Dinding rumah hanya diikat pada tiang luar. Penyebutan atap rumah Bugis selain atap berlereng dua, ada sebutan atap prisma segitiga yang memanjang ke belakang (Rahmansah dan Bakhrani Rauf, 2014). Ada juga yang menyebut atap rumah Bugis sebagai atap pelana dengan sudut $45^{\circ}$ (Matthes, B.F. 1874, dalam Syarif, dkk .2016)

Rumah Bugis terdiri dari 3 bagian, seperti bentuk tubuh manusia. Bagian bawah yang disebut Awa Bola atau Awasao diibaratkan sebagai kaki, bagian tengah yang disebut AleKawa atau Ale-bola diibaratkan sebagai tubuh, dan bagian atas disebut Botting Langi atau Rakkeang diibaratkan sebagai kepala. Hal ini juga dikaitkan dengan konsep makrokosmos (alam raya) yang juga memiliki tiga bagian, yaitu dunia bawah, dunia tengah, dan dunia atas. Pandangan ini diwujudkan dalam dunia mikrokosmos yaitu rumah Bugis (Anwar, Idwar. 2007).

Adapun fungsi masing-masing ruang ruang dalam rumah Bugis adalah: (1) Awa Bola atau Awasao adalah ruang di bagian bawah rumah (kolong) difungsikan sebagai kandang ternak, untuk menyimpan alat-alat pertanian atau alat penangkap ikan dan sebagainya. (2) Ale-Kawa atau Ale-bola adalah ruang di bagian tengah yang terbagi menjadi ruang tidur, ruang untuk menerima tamu, ruang makan dan dapur. (3) Botting Langi atau Rakkeang adalah untuk menyimpan bahan pangan dan benda-benda pusaka dan ruang untuk anak perempuan yang belum menikah (Pelras, 2006 : 265).

Dalam pandangan masyarakat Bugis pembagian rumah Bugis dalam 3 tingkat merupakan ekspresi penyembahan dan penghormatan kepada tiga dewa yang menguasai tiga dunia, yaitu Dewa Langi, Dewa Malino dan Dewa UwaE. Dewa Langi, yaitu dewa yang menguasai langit, Dewa Malino yaitu dewa yang menguasai bumi dengan segala isinya, dan Dewa UwaE yang menguasai tanah, sungai, dan laut (Yunus, 1999 : 198). 


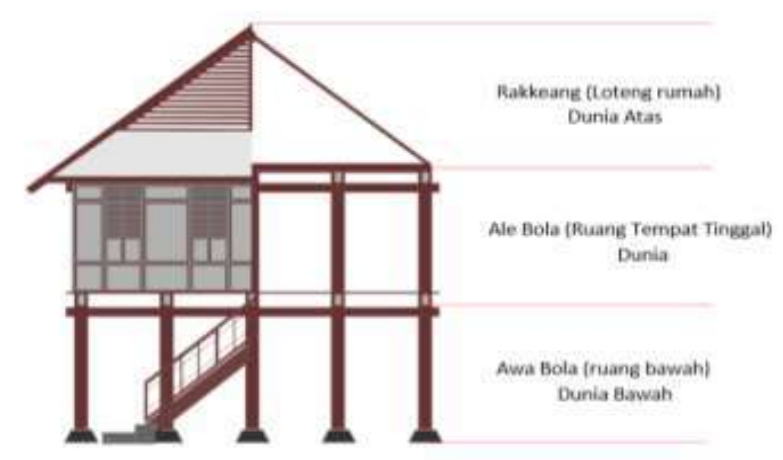

Gambar 1. Pembagian ruang spasial rumah tradisional Bugis

Sumber: http://kasuwiyang9.blogspot.co.id, 2019

Rumah Suku Bugis yang terdapat di Sulawesi bentuknya adalah panggung yang disangga oleh tiang-tiang kayu yang tingginya sekitar 2 meter dari permukaan tanah. Hal ini berbeda dengan bentuk yang rumah Bugis di Desa Kemojan, yang tiang penyangganya lebih pendek dibandingkan dengan rumah Suku Bugis yang ada di Sulawesi Selatan. Perbedaan tersebut dikarenakan ketersediaan bahan baku kayu di Desa Kemojan yang tidak melimpah seperti di Sulawesi Selatan. Selain itu rumah Bugis dibangun menyesuaikan dengan bentuk rumah suku Jawa dan Madura yang tidak berupa rumah panggung. Alasan lain adalah menghindari dan melindungi agar anak-anak yang masih kecil tidak jatuh dari rumah yang tinggi (Wawancara dengan Abdullah, tanggal 12 Maret 2019)

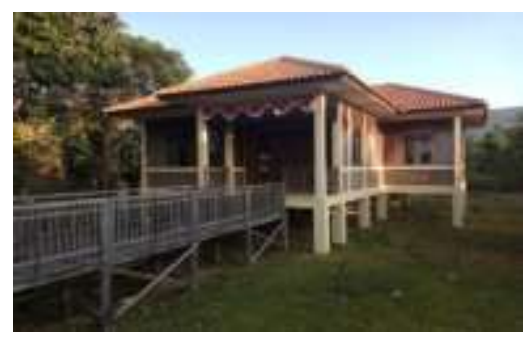

Gambar 2.Rumah Bugis yang menyerupai bentuk asli rumah Suku Bugis di Sulawesi Selatan (Sumber : Dokumentasi Pribadi)

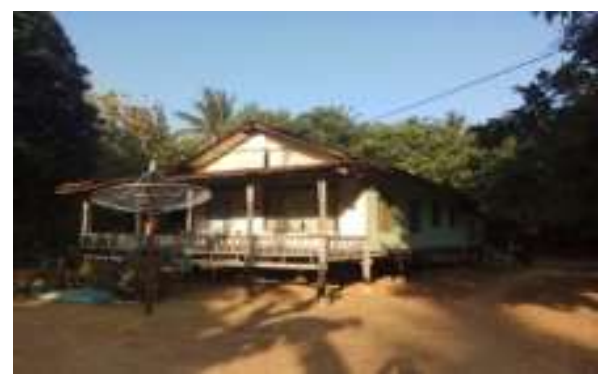

Gambar 2. Rumah suku Bugis di Dusun Batulawang, Desa Kemojan Karimunjawa (Sumber : Dokumentasi Pribadi) 
Rumah Bugis terbagi dalam tiga ruangan yaitu ruang depan, ruang tengah, dan ruang belakang. Ruang depan yang disebut Lontang Risaliweng memiliki beberapa fungsi, yaitu untuk menerima tamu, kamar tidur tamu, tempat musyawarah, dan kegiatan lain yang bersifat umum. Ruang tengah yang disebut Lontang Ritengnga berfungsi untuk kamar tidur kepala keluarga beserta istri, kamar tidur anak-anak yang belum dewasa, dan ruang makan. Ruang belakang yang disebut Lontang Rilaleng berfungsi sebagai kamar tidur orang-orang lanjut usia dan gadis remaja (Jumran, 2010). Ruang untuk dapur yang disebut dapureng berfungsi untuk melayani kebutuhan anggota keluarga biasanya terletak di bagian belakang atau samping rumah (Nurhuzna, dkk, 2012).

Karena bentuk rumah Bugis yang ada di Desa Kemojan agak berbeda ketinggiannya dengan rumah Bugis di Sulawesi Selatan, maka ada perubahan fungsi ruang-ruang di dalam rumah Bugis di Desa Kemojan. Atap rumah Bugis di Desa Kemojan yang tidak terlalu tinggi menciptakan Botting Langi atau Rakkeang (ruang di bawah atap) yang tidak terlalu luas, sehingga tidak dapat difungsikan sebagai tempat tidur gadis remaja. Ruang ini hanya dipakai untuk menyimpan peralatan rumah tangga dan makanan-makanan matang. Demikian juga dengan kolong atau bagian bawah rumah yang tidak terlalu tinggi, tidak dapat difungsikan sebagai kandang ternak dan penyimpanan alat-alat pertanian atau alat mencari ikan, sehingga dibiarkan kosong (Wawancara dengan Depadu pada tanggal 19 Maret 2019).

\subsection{Upaya Pemertahanan Rumah Bugis di Desa Kemojan}

Rumah Bugis merupakan hasil budaya masyarakat Bugis di Desa Kemojan dan mengandung nilai-nilai filosofi yang tinggi. Orang Bugis memandang rumah memiliki arti yang sangat penting dalam kehidupan manusia. Rumah bukan hanya sebagai tempat tinggal tetapi juga sebagai inti dalam kehidupan manusia, karena rumah menjadi tempat manusia dilahirkan, diasuh, dididik, kawin, dan meninggal. Sedemikian penting arti rumah dalam kehidupan manusia, maka membangun rumah harus memperhatikan, mengikuti tradisi dan kepercayaan yang sudah ada sejak dahulu dan diwariskan secara turun temurun dari leluhur. Untuk itu masyarakat Bugis Desa Kemojan berupaya tetap mempertahankan rumah Bugis sebagai warisan budaya. Rata-rata umur bagunan rumah Bugis sudah tua, bahkan ada yang dibangun sejak generasi pertama orang Bugis yang datang ke desa Kemojan.

Rumah Bugis dalam bentuk rumah panggung sudah menjadi hunian masyarakat kepulauan di Indonesia sejak dahulu. Rumah panggung dianggap dapat menghindarkan pengguninya dari bahaya banjir, gempa, ancaman binatang buas dan gangguan mahlukmahlug gaib. Dalam kepercayaan masayarakat Bugis di Desa Kemojan, di dunia ini ada mahluk mistis yaitu mahluk jadi-jadian yang dapat menyerupai binatang atau bentuk-bentuk yang menjijikkan seperti kotoran dan sebagainya. Untuk menghindari gangguan mahluk jadijadian ini orang-orang Bugis membangun rumah-rumah panggung yang tinggi. Dalam kepercayaan orang Bugis, yaitu bahwa atap rumah tidak layak menggunakan atap dari tanah liat, karena manusia yang hidup seharusnya berada di atas tanah. Kalau rumah menggunakan atap tanah dianggap seperti orang mati yang berada di bawah tanah. Kepercayaan ini sampai saat ini masih banyak yang mempercayainya, walaupun tidak ada relevansinya dengan kehidupan keseharian mereka (Wawancara dengan Rusing, tanggal 20 Maret 2019) .

Nilai-nilai kegotongroyongan dalam pembangunan rumah Bugis di Desa kemojan, merupakan hal positif yang masih lestari. Dalam membangun rumah Bugis, kerangka bangunan di rancang dan dipasang di bawah. Kerangka rumah dibuat dengan sistem knock down,tanpa pasak dan paku. Setelah kerangka jadi baru ditegakkan. Diperlukan tenaga orang banyak untuk menegakkan kerangga rumah tersebut. Nilai-nilai kegotongroyangan ini masih terpelihara di Desa Kemojan. Hal yang sama juga terjagi ketika rumah Bugis akan dipindahkan ke lokasi lain. Rumah tersebut diangkat dan digotong beramai-ramai oleh warga. 
Masyarakat Bugis di Desa Kemojan yang semula membangun rumah Bugis tidak terlalu tinggi, lama kelamaan ketika tiang penyangga rumah lapuk, maka mereka memotong sebagian tiang yang sudah lapuk. Untuk mengganti tiang-tiang rumah Bugis dengan kayu yang baru memerlukan biaya yang besar karena harga kayu yang mahal. Jadi rumah Bugis yang semula tidak terlalu tinggi, semakin pendek tiangnya.

Di Desa Kemojan tidak semua orang Bugis membangun rumahnya dalam bentuk rumah Bugis. Generasi muda Bugis biasanya menempati rumah Bugis peninggalan orang tuanya, sedangkan genarasi Bugis yang lain ada yang membangun rumah dalam bentuk rumah modern.

Setelah Karimunjawa populer sebagai destinasi wisata, Desa Kemojan terkena imbasnya. Banyak turis domestik maupun mancanegara yang berkunjung ke Desa Kemojan untuk menikmati keunikan budaya masyarakat Bugis dalam bentuk rumah-rumah Bugis.

Seiring dengan perkembangan wisata Karimunjawa, terjadi perubahan dalam mata pencaharian penduduk. Penduduk yang semula banyak yang bekerja sebagai petani, nelayan maupun pedagang, sekarang bekerja di sektor wisata, baik sebagai pemandu wisata, biro jasa wisata dan persewaan home stay. Dalam sektor wisata ini kreativitas penduduk suku Bugis perlu diapresiasi, karena mereka membangun home stay dalam bentuk rumah Bugis ditepitepi pantai, seperti pantai Asari Timo' (Timo dalam bahasa Bugis artinya Timur) dan pantai Laendra yang letaknya di Barat (Bare')

\section{Simpulan}

Desa Kemojan yang sudah terkenal dengan keindahan alamnya semakin indah dengan budaya masyarakat Bugis yang ditampilkan dalam bentuk rumah-rumah Bugis yang unik. Keindahan budaya ini perlu dipertahankan dan dilestarikan karena akan menjadi kekayaan daerah.

Kesadaran masyarakat Desa Kemojan, baik masyarakat Bugis maupun masyarakat suku lain dalam pelestarian budaya ini sangat tinggi. Mereka menganggap budaya Bugis adalah budaya milik seluruh masyarakat Desa Kemojan. Upaya-upaya membangun rumah Bugis untuk tujuan wisata merupakan hal positif, walaupun rumah Bugis yang dibangun untuk tujuan tersebut masih sedikit. Untuk renovasi rumah-rumah Bugis yang sudah lama, masyarakat kesulitan karena dana yang harus mereka keluarkan sangat mahal. Diharapkan kegiatan pariwisata yang semakin ramai juga berdampak pada peningkatan penghasilan masyarakat, yang nantinya berdampak pula pada perbaikan lingkungan dan rumah Bugis yang mereka tempati.

Kegiatan gotong royong dalam pembangunan rumah Bugis diharapkan menjadi teladan bagi generasi muda Desa Kemojan dan dapat menjadi pelajaran tentang hidup harmonis dengan berbagai suku di tanah perantauan. Nilai-nilai falsafah yang terkait dengan pembangunan Rumah Bugis hendaknya diwariskan kepada generasi muda sebagai kearifan lokal yang tidak ternilai harganya. Hal ini sangat berguna untuk menguatkan identitas suku Bugis diperantauan.

\section{Daftar Pustaka}

Abdullah, Hamid.1985. Manusia Bugis Makassar, Suatu Tinjauan Historis Terhadap Pola Tingkah Laku dan Pandangan hidup Manusia Bigis Makassar. Jakarta : Inti Idayu Press.

Anwar, Idwar. 2007. Ensiklopedi Kebudayaan Luwu. Makassar : Pustaka Sawerigading. 
Creswell, J.W. 2008. Research Design: Qualitative, Quantitative, and Mixed Methods Approaches. California: Sage Publications, Inc.

Danim, Sudarwan.2002. Menjadi Peneliti Kualitatif. Bandung: Pustaka Setia.

Gottschalk, Louis (2008). Mengerti Sejarah (diindonesiakan oleh Nugroho Notosusanto). Jakarta: UI-Press.

Jumran, 2010. Perubahan Bentuk Hunian Suku Bajo Akibat Pengaruh Interaksi Dengan Suku Bugis Di Kabupaten Bone. Surabaya : ITS.

Kesuma, Andi Ida. 2004.Migrasi dan Orang Bugis. Yogyakarta: Penerbit Ombak.

Latief, Mochamad Chaerul.2016. Komunikasi Beda Gender dalam Masyarakat Bugis di Desa Kemujan Kepulauan Karimunjawa, dalam Jurnal The Messenger, Volume VIII, Nomor 2, Edisi Juli.

Marvati, A.B. 2004.Qualitative Research In Sociology: An Introduction. Thousand Oaks: sage Publ. Inc.

Miles, Matthew B. dan A. Michael Huberman, (1992). Analisis Data Kualitatif: Buku Sumber tentang Metode-metode Baru. Jakarta: UI-Press.

Nurhuzna, Artiza dkk, 2012. Transformasi Fungsi Dan Bentuk Arsitektur Bugis-Makassar Di Pesisir Pantai Buti Merauke. Makassar : Unhas.

Puguh,Dhanang Respati, dkk. 2016. Strategi Adaptasi Ekonomi Nelayan Bugis Batulawang, Kemujan, Karimunjawa dalam Jurnal Sejarah Citra Lekha, Vol. 1, No. 1.

Rahmansah dan Rauf, Bakhrani. 2014. Arsitektur Tradisional Bugis Makassar. Jurnal Forum Bangunan : Volume 12 Nomor 2, Juli 2014

Rapoport, Amos. 1969. House, Form and Culture. Englewood Cliffs, N.J.: Prentice Hall.

Syarif, dkk .2016. Prinsip-prinsip Pemilihan Material Bangunan Tradisional Bugis (Berdasarkan Pendapat Panrita Bola dan Panre Bola) dalam Prosiding Temu Ilmiah IPLBI 2016

Suliyati, Titiek.2016. Etnis Bugis Di Kepulauan Karimunjawa: Harmoni dalam Pelestarian Budaya dan Tradisi, dalam Sabda, Volume 11.

Wasilah \& Hildayanti, 2016. Filosofi Penataan Ruang Spasial Vertikal Pada Rumah Tradisional Saoraja Lapinceng Kabupaten Barru. Jurnal RUAS, Volume 14 No 2, Desember 2016, ISSN 1693-3702 70

Yunus, Pangeran Paita. 1999. Unsur-Unsur Kemahiran Lokal (Local Genius) dalam Ragam Hias Bugis: Kajian Ragam Hias pada Rumah Tradisional Bugis Sulawesi Selatan dalam Unsur-Unsur Estetika Bentuk. Tesis pada Program Magister Seni Rupa dan Desain, Program Pascasarjana, Institut Teknologi Bandung, Tahun 1999.

Sumber dari internet :

(http://ace-informasibudaya.blogspot.com, diunduh 1 Mei 2019)

\section{Daftar Informan}

1. Nama : Abdullah

Alamat : Dusun Batulawang Desa Kemujan, Karimunjawa

Umur :65 Tahun

2. Nama : Depadu

Alamat : Dusun Batulawang Desa Kemujan, Karimunjawa

Umur :72 Tahun

3. Nama : Rusingi

Alamat : Dusun Batulawang Desa Kemujan, Karimunjawa

Umur : 82 Tahun 